\title{
System dynamics analysis of COVID-19 prevention and control strategies
}

\author{
Shuwei Jia ${ }^{1,2}$ (D) Yao $\mathrm{Li}^{1} \cdot$ Tianhui Fang $^{3}$ \\ Received: 23 May 2021 / Accepted: 6 August 2021 / Published online: 16 August 2021 \\ (C) The Author(s), under exclusive licence to Springer-Verlag GmbH Germany, part of Springer Nature 2021
}

\begin{abstract}
The COVID-19 pandemic now affects the entire world and has many major effects on the global economy, environment, health, and society. Focusing on the harm COVID-19 poses for human health and society, this study used system dynamics to establish a prevention and control model that combines material supply, public opinion dissemination, public awareness, scientific and technological research, staggered work shifts, and the warning effect (of law/policy). Causal loop analysis was used to identify interactions between subsystems and explore the key factors affecting social benefit. Further, different scenarios were dynamically simulated to explore optimal combination modes. The main findings were as follows: (1) The low supervision mode will produce a lag effect and superimposed effect on material supply and impede social benefit. (2) The strong supervision mode has multiple performances; it can reduce online public opinion dissemination and the rate of concealment and false declaration and improve government credibility and social benefit. However, a fading effect will appear in the middle and late periods, and over time, the effect of strong supervision will gradually weaken (but occasionally rebound) and thus require adjustment. These findings can provide a theoretical basis for improving epidemic prevention and control measures.
\end{abstract}

Keywords COVID-19 · System dynamics · Emergency supply $\cdot$ Prevention and control strategy

\section{Introduction}

The coronavirus disease 2019 (COVID-19) pandemic has posed serious threats to human health, society, and cities sustainability (Irfan et al. 2020; Elavarasan et al. 2021), placing

Responsible Editor: Lotfi Aleya

Shuwei Jia

shuweijia999666@163.com

Yao Li

yaoli@vip.henu.edu.cn

Tianhui Fang

15921011580@163.com

1 Business School, Henan University, Jinming District, Kaifeng, Henan 475004, People's Republic of China

2 College of Information and Management Science, Henan Agricultural University, 15 Longzi Lake Campus, Zhengzhou East New District, Zhengzhou, Henan 450046, People's Republic of China

3 Business School, East China University of Science and Technology, Shanghai 200237, People's Republic of China great pressures on governments to intervene (World Health Organization 2020). This has created an urgent need to find strategies to effectively reduce the harm caused by COVID-19 as well as any future epidemics. Many studies have investigated emergency management and epidemic prevention and control strategies related to COVID-19. Epidemiological studies have established prediction models based on existing data (Zhou et al. 2020) and have identified the phenomenon of human transmission in China (Riou and Althaus 2020). Hassen et al. (2021) proposed a susceptible-infectious-removed (SIR)-Poisson model to predict the range of future infections. Hoch et al. (2018), meanwhile, established a susceptible-infectious-removed-susceptible (SIRS) model to simulate dynamic infection in a multigroup system. In the aspect of transmission dynamics of COVID-19, Zhao et al. (2021) discussed the importance of individual-specific case management strategies to mitigate the COVID-19 pandemic by lowering the transmission risks of potential super-spreaders with priority. Coccia (2020a) proposed the Index c that quantifies to estimate the environmental risk of exposure of cities to future epidemics of COVID-19. Scholars described some factors in society driven by the interaction between air pollution (Razzaq et al. 2020; Coccia 2021a; Coccia 2021b) and 
meteorological factors (Coccia 2020b; Irfan et al. 2021a), especially for $\mathrm{NO}_{2}$ and $\mathrm{PM}_{2.5}$ (Iqbal et al. 2021). Rahimi et al. (2021) found that the bidirectional association between COVID-19 and the environment and appealed countries need to pay extra attention to sustainable development themes and goals. Such studies provide a reference for improving epidemic prevention and control policies.

Regarding specific prevention and control strategies, $\mathrm{Li}$ (2020) provided practical suggestions in areas such as shopping, walking and exercise, preventive measures at home, and personal protection. Using block chain technology, Marbouh et al. (2020) identified ways to improve data authenticity by reducing delays in regulatory approvals while also reducing the degree of public panic. Wang et al. (2021) believed that heterogeneous interventions can reduce both the peak infection rate and the total infected population.

In terms of science and technology, studies have proposed intelligent algorithms to predict the number of confirmed cases (Roosa et al. 2020; Pirouz et al. 2020). Hu et al. (2020) and, meanwhile, proposed an AI system for the realtime prediction of COVID-19 to estimate the lifetime of the virus. Hamed et al. (2021) introduced a classical classification algorithm to efficiently and accurately classify COVID-19 cases. Malki et al. (2021) developed a machine learning model to predict the estimation of the spread of the COVID-19 infection in many countries. To ensure data security for infected patients, one study developed an improved method for encrypting images from coronavirus patients' computed tomography chest scans (Reyad and Karar 2021).

Regarding emergency management strategies, system dynamics has been used to identify the key factors affecting the speed of emergency material allocation and transportation; specifically, reducing the time lag in government response to emergency information and improving emergency management material scheduling were found to improve the speed of emergency material allocation and transportation ( $\mathrm{Li}$ et al. 2015). Examining public opinion dissemination with regard to water pollution events, Yu et al. (2015) proposed that public opinion can be better managed by improving media transparency, speeding up government response, and enhancing the government's crisis management abilities. Another study, meanwhile, investigated panic buying behaviors in the context of events such as the Fukushima Daiichi nuclear disaster, Sichuan earthquake, swine flu pandemic, and SARS (Zhao et al. 2015). Through the comparative analysis of the first and second wave of COVID-19 to assess its impact on health of people, and then design effective countermeasures to reduce the negative benefits (Coccia 2021c).

COVID-19 poses both opportunities and challenges for social development (Hoang et al. 2021). Generally, increased investment in clean energy has had positive effects on the economy and employment (Mehrotra et al. 2020; Hepburn et al. 2020) while helping to achieve emission reduction targets
(Kuzemko et al. 2020). COVID-19, meanwhile, has had serious effects on the global economy and on energy systems (AbuRayash and Dincer 2020; Chakraborty and Maity 2020) via business closures and the suspension of public transport (Wright 2020). The economic harm caused by COVID-19 includes supply chain interruptions and food crises (Carmen and Reinhart 2020). With regard to environmental effects, Elavarasan et al. (2020) noted that border closures and travel bans have greatly reduced the use of personal vehicles.

The abovementioned research has investigated emergency management strategies from different perspectives and made corresponding policy suggestions, providing useful references for improving emergency management and control policies. However, in the face of a major pandemic, prevention and control measures still have the following deficiencies:

(1) In the early stages of COVID-19, poor management of public opinion dissemination and weak incentive measures for the supply of materials led to a widespread phenomenon of "panic buying" in supermarkets.

(2) The medium- and long-term effects of certain prevention and control measures remain unclear, leading to significant short-term effects and "fading" long-term effects. For example, some urban communities adopted unified travel time frames, which resulted in a "gathering phenomenon" among shoppers, thus increasing the risk of transmission.

In view of the above, this study aimed to expand the research on improving the long-term effects of epidemic prevention and control countermeasures in urban settings. A new mode was designed that combines prevention and control countermeasures in terms of economic means (e.g., incentives such as subsidies), legal means (e.g., the warning effect of policies and regulations), administrative means (e.g., enhancing government credibility and increasing science publicity, education, and training), and technical means (e.g., R\&D investment, professional talent introduction, platform support). Dynamic simulation was used to analyze negative effects such as panic buying rates, concealment rates, and delayed reporting rates for emergency supplies. Finally, this study explored effective prevention and control strategies to improve existing management and control modes.

\section{Materials and methods}

\section{System dynamics modeling of the factors affecting social benefit}

Figure 1 shows the causal loop diagram. With regard to public opinion dissemination and the harm caused by events, the main loops are Loop 1-Loop 6. 


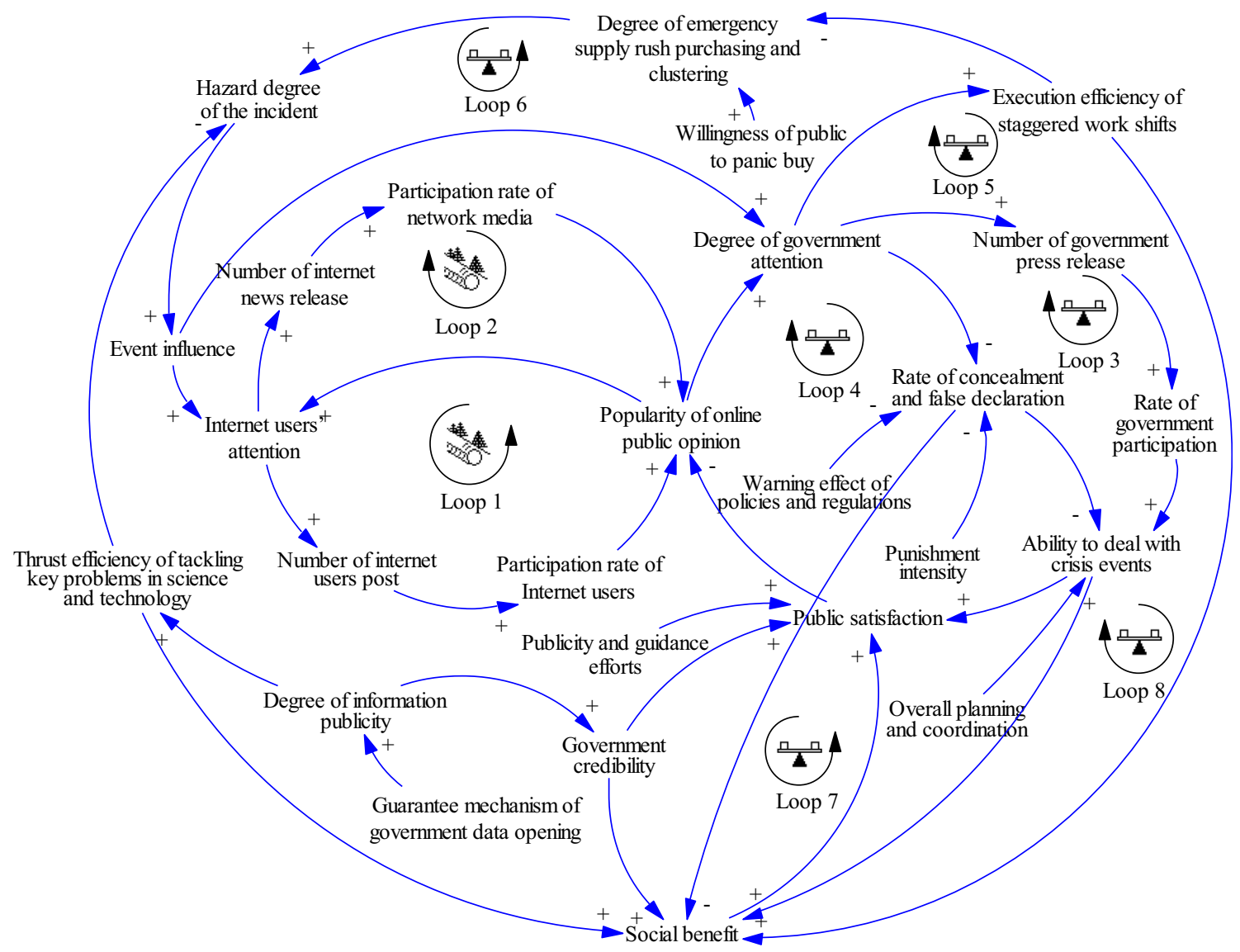

Fig. 1 Causal relationship diagram

Loop 1 The increasing dissemination of online public opinion stimulates the attention of netizens, thus increasing the number of posts and the participation rate of netizens, ultimately intensifying online public opinion dissemination. This loop is a positive feedback loop. At first, public opinion dissemination starts to increase, and under the effect of the loop, such dissemination is further strengthened.

Loop 2 Loop 2 is also a positive feedback loop, where online public opinion dissemination increases through the growth of online media participation. Therefore, Loop 1 and Loop 2 intensify the heat of online public opinion through netizens and through online media, respectively. The improved openness of government information will improve the boosting efficiency of science and technology research, reduce the influence of events, reduce attention from Internet users, reduce the participation rate of online media, and finally cool public opinion.

Loop 3 Increased public opinion dissemination online will spur the government to pay more attention, and the amount of news releases will correspondingly increase to improve government participation. Improved government participation will improve the ability to deal with crisis events and thereby increase public satisfaction, improve government credibility, and reduce the intensity of online public opinion. In addition, an overall coordination strategy can improve the ability to deal with crisis events and ultimately reduce the intensity of online public opinion. This is a negative feedback loop. Under the effect of this loop, public opinion dissemination is alleviated to a certain extent.

Loop 4 Loop 4 is also a negative feedback loop that reduces the rate of concealment and delays in reporting through warning effects (legal measures) and punishment (economic measures). The reduction of concealment and delays in reporting can improve the ability to deal with crisis events, thereby increasing public satisfaction, improving government credibility, and ultimately reducing the dissemination of online public opinion.

Loop 5 and Loop 6 Loop 5 and Loop 6 are both negative feedback loops. Loop 5 can increase social benefit by improving staggered travel efficiency, thus improving public satisfaction and government credibility and cooling online public opinion. Loop 6 introduces a staggered travel strategy according to the amount of rush purchasing of emergency materials to mitigate that 
phenomenon and reduce the overall harm and influence of the event.

Loop 7 and Loop 8 In terms of improving social benefit, the main loops are Loop 7 and Loop 8. Loop 7, for example, is a negative feedback loop. The key measure is to reduce the rate of concealment and delays by strengthening the warning effect and punishment via policies and regulations, which will finally achieve the purpose of improving social benefit.

In summary, the key factors for reducing the dissemination of online public opinion are improving government credibility, enhancing science and technology research efficiency, and improving the ability to deal with crisis events. Among them, administrative means include strengthening publicity and guidance and improving the efficiency of staggered travel to enhance public satisfaction. Through a combination of technical measures, economic measures, administrative measures, and policies and regulations, we can improve government data and information disclosure to improve the efficiency of science and technology research. Improving information openness is conducive to improving government credibility. Improving government supervision, communication efficiency, prediction accuracy, and government response time will also improve government credibility. Therefore, coordinating multiple policies can provide a guarantee for effectively improving government credibility and the efficiency of tackling scientific and technological problems. Measures for improving the ability to deal with crisis events include strengthening the warning effect of policies and regulations (legal measures), increasing punishment for concealment and delay (economic measures), and improving the overall coordination (administrative measures). This combination of legal, economic, and administrative means can effectively improve the ability to deal with crisis events.

Based on the loop analysis described above, combined with existing research ( $\mathrm{Li}$ et al. 2015; Yu et al. 2015), a system dynamics model was established for prevention and control strategies during epidemic emergencies (see Fig. 2).

\section{Data sources}

The model mainly includes public opinion dissemination, emergency material supply, and social benefit subsystems. This study took the demand and supply of agricultural products (e.g., vegetables) in Zhengzhou during the period of epidemic prevention and control as an example. Data sources were divided into three types: statistical yearbook + simple calculation (e.g., determining the initial value of emergency material inventory in Zhengzhou), real situation + simple calculation (e.g., constructing an emergency material demand prediction model; this needed to consider three aspects, per capita demand, urban population development trend, and emergency material rush purchasing; urban population development needed to be determined according to the average population of Zhengzhou and actual changes in recent years), and the existing literature (e.g., existing work on online public opinion dissemination, government attention, publicity and guidance, social benefit).

\section{Data analysis and variables measure}

\section{Public opinion dissemination subsystem}

The main variables of this subsystem include degree of government attention, participation rate of Internet users, participation rate of network media, degree of government data sharing, government credibility, public satisfaction, publicity and guidance efforts, and popularity of online public opinion. The typical equations are as follows:

(1) Popularity of online public opinion $=k_{1} *$ participation rate of Internet users* $100+k_{2} *$ participation rate of network media* $100-k_{3} *$ public satisfaction

(2) Guarantee mechanism of government data opening $=m_{1} *$ financial support $+m_{2} *$ management level $+m_{3} *$ technical support $+m_{4} *$ policies and regulations

(3) Degree of government data sharing= WITH LOOKUP (guarantee mechanism of government data opening, ([( 0 , $0)$ - $(1,100)],(0,0),(0.1,5),(0.2,10),(0.3,15),(0.4,25)$, $(0.5,40),(0.6,60),(0.7,75),(0.8,85),(0.9,90),(1,95)))$

(4) Government credibility $=0.2 *$ degree of information publicity $+0.2 *$ supervision of emergency material dispatch $* 100+0.2 *$ communication efficiency*100+ $0.2 *$ prediction accuracy $* 100+0.2 *$ reaction efficiency* 100

(5) Reaction efficiency $=$ WITH LOOKUP (response time, $([(0,0)-(10,1)],(0,1),(1,0.8),(2,0.65),(3,0.5),(4$, $0.4),(5,0.35),(6,0.3),(7,0.25),(8,0.2),(9,0.1),(10$, $0)))$

Popularity of online public opinion was determined by the participation rate of Internet users, the participation rate of Internet media, and public satisfaction, where $0<k_{1}<1$, $\sum_{i-1}^{3} k_{1}=1$ Factors affecting the guarantee mechanism of government data opening included financial support, management level, technical support, and policies and regulations, where $0<m_{1}<1, \sum_{m-1}^{4} m_{1}=1$.

This subsystem combines economic measures (e.g., financial support), administrative measures (e.g., improving management level), technical measures (e.g., technical support), and legal measures (e.g., policies and regulations) to improve the openness of government data and information and thereby enhance government credibility. This, in turn, can enhance public satisfaction and reduce the intensity of online public opinion dissemination. 


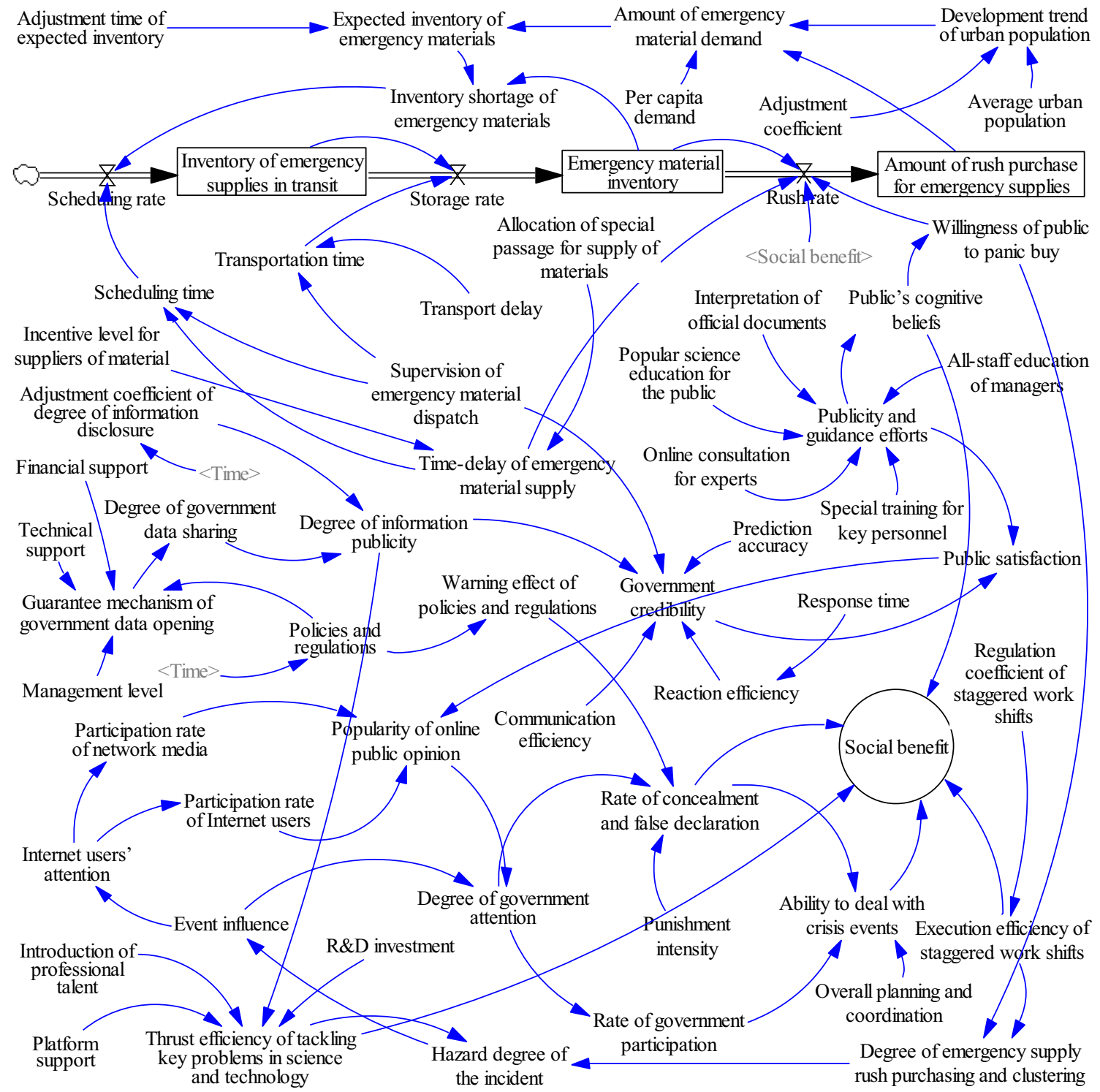

Fig. 2 System dynamics model of factors affecting social benefit in the context of major epidemic emergencies

\section{Emergency material supply subsystem}

(1) Emergency material inventory= INTEG (storage raterush rate, $4.5 \mathrm{e}+006)$

(2) Amount of rush purchase for emergency supplies= INTEG (rush rate, 0 )

(3) Amount of emergency material demand= per capita demand*development trend of urban population $+\alpha *$ amount of rush purchase for emergency supplies

(4) Publicity and guidance efforts $=\lambda_{1} *$ special training for key personnel $+\lambda_{2}{ }^{*}$ all-staff education of managers $+\lambda_{3}{ }^{*}$ online consultation for experts $+\lambda_{4} *$ interpretation of official documents $+\lambda_{5}$ *popular science education for the public
Publicity and guidance efforts were determined by the special training for key personnel, the all-staff education of managers, the online consultation for experts, the interpretation of official documents, and popular science education for the public, where $0<\lambda_{i}<1, \sum_{\lambda-1}^{4} \lambda_{i}=1$ The amount of emergency material demand was determined by per capita demand, the development trend of the urban population, and the amount of rush purchasing for emergency supplies, where $0<\alpha<1$.

Through the combination of administrative means (e.g., allocating special passage for material supply) and economic means (e.g., incentives for material suppliers), this subsystem can shorten delays in emergency material supply, improve scheduling speed, and reduce the inventory shortages of emergency materials. 


\section{Social benefit subsystem}

Factors affecting the social benefit subsystem included thrust efficiency of tackling key problems in science and technology, execution efficiency of staggered work shifts, ability to deal with crisis events, rate of concealment and false declaration, and public's cognitive beliefs. The typical equations are as follows:

(1) Social benefit $=n_{1}$ *thrust efficiency of tackling key problems in science and technology $+n_{2}$ *execution efficiency of staggered work shifts $+n_{3}$ *public's cognitive beliefs/ $100-n_{4} *$ rate of concealment and false declaration $+n$ $5^{*}$ ability to deal with crisis events $/ 100$. Where $0<n_{1}<1, \sum_{n-1}^{5} n_{1}=1$

(2) Rate of concealment and false declaration $=0.1 * \mathrm{EXP}(-$ degree of government attention/100)+ $0.4 * \mathrm{EXP}(-$ warning effect of policies and regulations) $+0.5 * \operatorname{EXP}(-$ punishment intensity)

(3) Thrust efficiency of tackling key problems in science and technology $=0.2 *$ platform support $+0.3 *$ introduction of professional talent $+0.25 * \mathrm{R} \& \mathrm{D}$ investment $+0.25 *$ degree of information publicity/100

(4) Ability to deal with crisis events $=0.4 *$ rate of government participation* $100+0.3 *$ overall planning and coordination* $100+0.3 * \operatorname{EXP}$ (-rate of concealment and false declaration)*100

\section{Results}

\section{Model test}

In Fig. $3 \mathrm{a}$, when the extreme value $=0.05$, the speed of the rush rate declines rapidly in the short term but is still rising in the medium and long term. When the extreme value $=0.95$, the speed of the rush rate will gradually stabilize.

Accordingly, in Fig. 3b, curve 1 also continues to rise (when the extreme value $=0.05$ ), while the rising speed of curve 2 is inhibited (when the extreme value $=0.95$ ). These results are consistent with reality; the model is therefore reasonable.

\section{Dynamic simulation analysis}

Administrative, economic, and technical measures were divided into three modes: low, medium, and strong. These were defined as current (scenario 1), current $+\Delta \mathrm{X}$ (scenario 2), and current $+2 \Delta X$ (scenario 3 ). Figure 4 shows the simulation results, assuming the initial value is 0.35 , and $\triangle \mathrm{X}=0.25$.
Figure $4 \mathrm{a}$ shows that the storage rate is still on the rise under the actions of scenario 1 and scenario 2, while under the strong supervision mode (scenario 3 ), it is gradually stabilized after the 30th day (curve 3).

In Fig. $4 b$, with the increasing degree of supervision, the speed of the rush rate will decline in varying degrees. Under the action of scenario 3 , after the 25th day, the rush rate will gradually stabilize. Similarly, from scenario 1 to scenario 3, the degree of government data sharing and information publicity are also greatly improved (Fig. $4 \mathrm{c}$ and d).

Figure 4 also shows that the gap between curve 1 and curve 3 gradually narrows. The results show that the increasing degree of supervision has a marginal decreasing effect on the improvement of the storage rate, rush rate, degree of government data sharing, and degree of information publicity. Therefore, the greater the degree of supervision, the better; this should follow the "moderate principle." In particular, Table 1 shows that compared to the initial scenario, the strong supervision mode can effectively reduce the rush rate and storage rate by $71.74 \%$ and $70.90 \%$, respectively, while the degrees of government data sharing and information publicity are increased by $97.99 \%$ and $98 \%$, respectively.

\section{Multiple performances of the strong supervision mode}

Scenario 3 is taken as an example to explore the multiple performances of the combined strategy through simulation; Figure 5 shows the results. Government credibility (Fig. 5a) and social benefit (Fig. 5c) continue to rise, the rate of concealment and false declaration decline (Fig. 5b), and online public opinion dissemination (Fig. 5d) declines significantly.

Table 2 (see Appendix) shows that government credibility is in the high range and government credibility and social benefit have increased by $24.31 \%$ and $14.93 \%$, respectively. The rate of concealment and false declaration have decreased by about $33.48 \%$, and online public opinion dissemination declined by $50.27 \%$.

\section{Discussion}

\section{Superimposed effect}

In Fig. 6a and b, as time goes by (after the 10th day), the curve shows a rising trend. The reasons may be as follows: A single limited travel time policy (e.g., 10:00-12:00 every day) in an urban community can lead to the phenomenon of shopper clustering (Buhat et al. 2021). The other reason could be a lack of residents' cognitive concepts (Ahmad et al. 2021; Irfan et al. 2021b), as well as the delay of emergency supplies. These factors can aggravate the phenomenon of "snapping up" emergency materials (Fig. 6a). With the continuous 
(a)

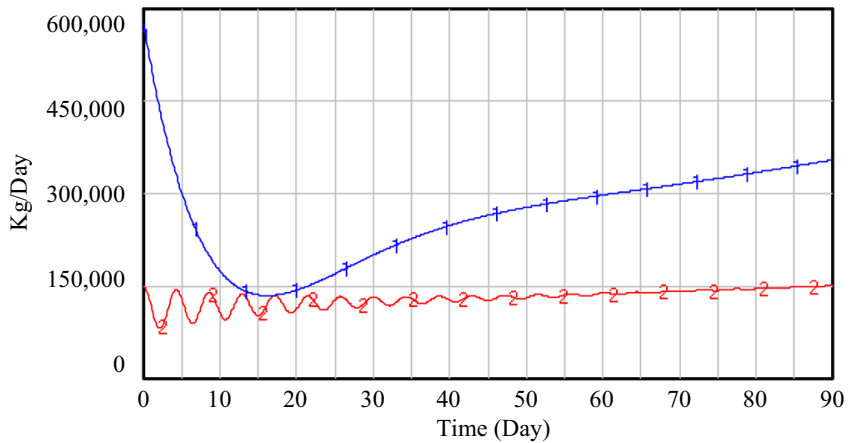

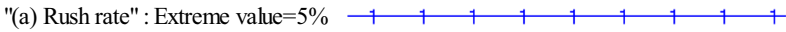

"(a) Rush rate" : Extreme value $=95 \% \quad \begin{array}{lllllllll}2 & 2 & 2 & 2 & 2 & 2 & 2 & 2\end{array}$ (b)

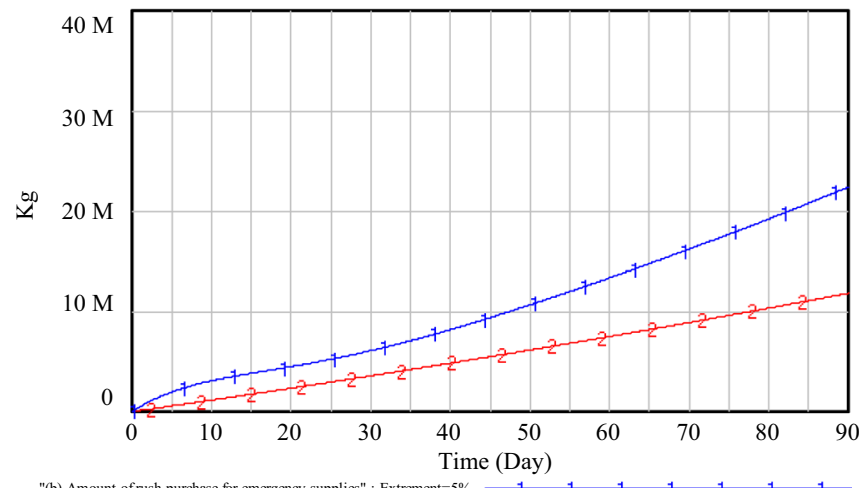

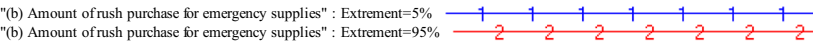

Fig. 3 Extreme condition test. a Rush rate; $\mathbf{b}$ amount of rush purchasing for emergency supplies

growth of the speed of rush purchasing, the amount of the rush purchasing of emergency materials also increases, which leads to higher demand, resulting in a sharp rise in the expected inventory of emergency materials.

Figure $6 \mathrm{c}$ and $\mathrm{d}$ show that under the low supervision mode, public satisfaction and the degree of government attention are in the lower middle level. On the one hand, although public satisfaction has been improved, the improvement is very

(a)

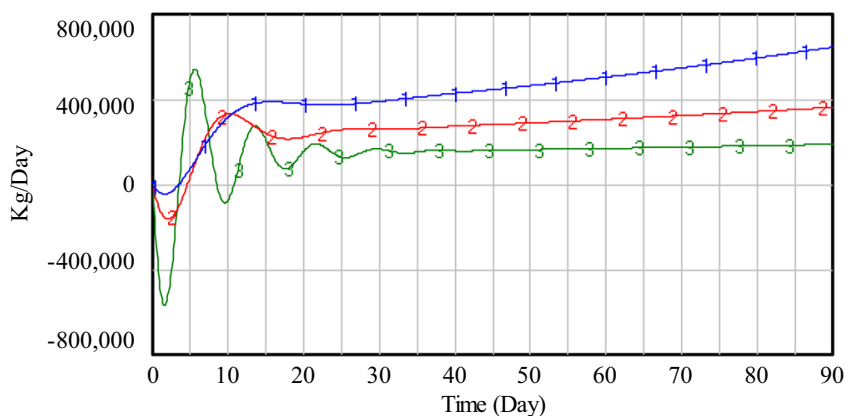

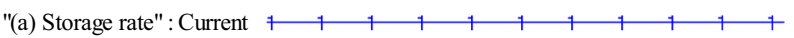

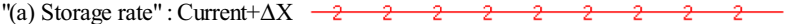

"(a) Storage rate" : Current $+2 \Delta \mathrm{X} \quad \begin{array}{llllllllll}3 & 3 & 3 & 3 & 3 & 3 & 3 & 3 & 3\end{array}$

(c)

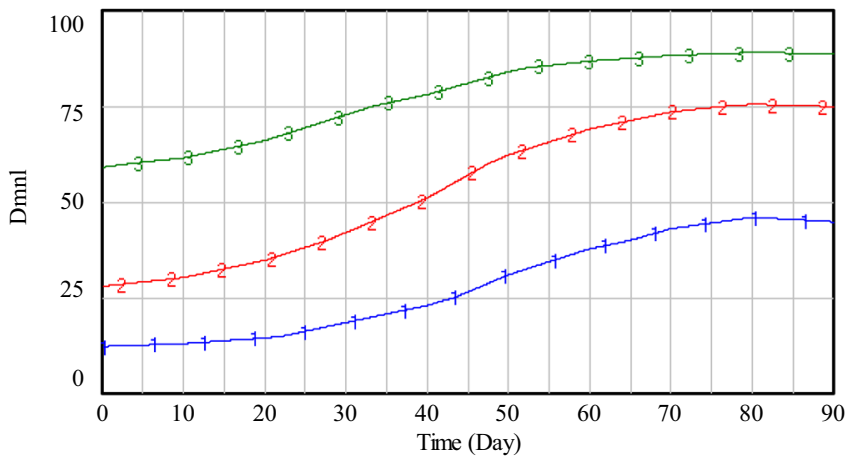

"(c) Degree of government data sharing" : Current
"(c) Degree of govermment data sharing" : Current $+\Delta \mathrm{X}$
"(c) Degree of govemment data sharing" : Current+ $+2 \Delta \mathrm{X}$ limited (Fig. 6c); with the development of the epidemic, the degree of government attention is declining (Fig. 6d). On the other hand, the negative effect of the spread of online public opinion and the existence of large concealment and delay rates increase the risk of "breaking out again" (Yu et al. 2015). More specifically, Table 3 (see Appendix) shows that the rush rate has increased by about $21.95 \%$, leading to an increase in the expected inventory of emergency supplies by about

(b)

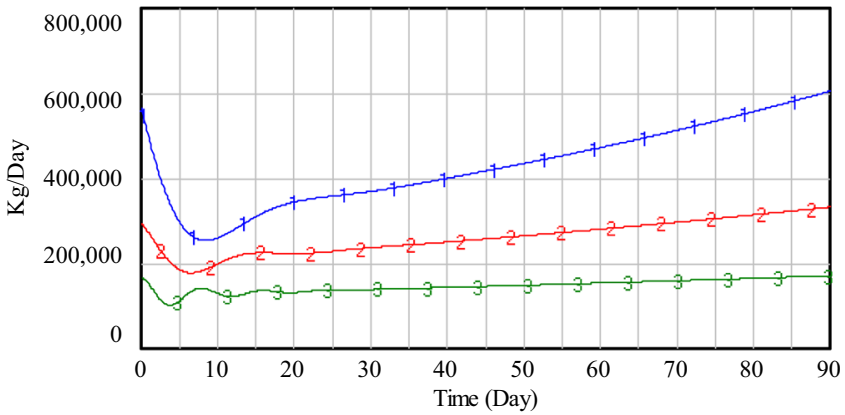

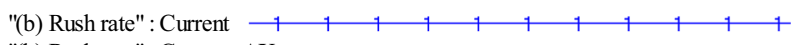
"(b) Rush rate" : Current $+\Delta X \quad \begin{array}{lllllllllll}2 & 2 & 2 & 2 & 2 & 2 & 2 & 2 & 2\end{array}$ "(b) Rush rate" : Current $+2 \Delta X \quad$\begin{tabular}{llllllllll}
\hline & 3 & 3 & 3 & 3 & 3 & 3 & 3 & 3 & 3
\end{tabular}

(d)

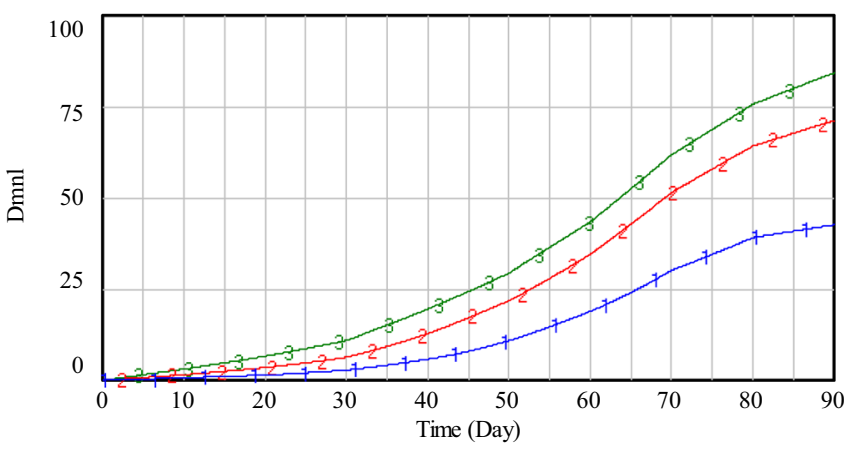

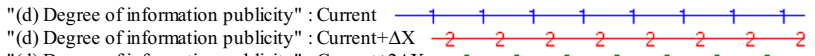

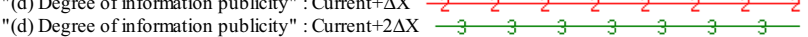

Fig. 4 Influence of different scenarios on main variables. a Storage rate; $\mathbf{b}$ rush rate; $\mathbf{c}$ degree of government data sharing; $\mathbf{d}$ degree of information publicity 
Table 1 Comparative analysis of different scenarios

\begin{tabular}{lllll}
\hline Variable & Scenario 1 (current) & Scenario 2 (current+ $\Delta \mathrm{X})$ & Scenario $3($ current+2 $\Delta \mathbf{X})$ & Variation $(\%)$ \\
\hline Storage rate (kg/day) & 646,205 & 362,725 & 188,034 & -70.90 \\
Rush rate (kg/day) & 606,027 & 333,130 & 171,259 & -71.74 \\
Degree of government data sharing & 44.80 & 74.85 & 88.70 & 97.99 \\
Degree of information publicity & 42.56 & 71.11 & 84.27 & 98.00 \\
\hline
\end{tabular}

$107.12 \%$. At the same time, public satisfaction only increased by $13.49 \%$, and degree of government attention decreased by about $4.22 \%$.

The superposition of multiple factors aggravates public panic, resulting in the phenomenon of "shoppers gathering" and "snapping up," which leads to an increased demand for and expected inventory of emergency materials, which further inhibits social benefit.

\section{Lag effect}

In Fig. 7a, the curve first rises rapidly (stage 1: before the 10th day), then decreases gradually (stage 2: between 10 and 20 days), and finally rebounds (stage 3 : after the 20th day). The results in Table 4 (see Appendix) show that the inventory shortage of emergency materials initially increased by about five times (stage 1), then decreased by about $31.25 \%$ (stage 2), rebounded after the 20th day, and continued to rise, increasing by $95.14 \%$ at the end of the simulation. The reason could be as follows: At first, the government gradually introduces a series of epidemic prevention and control measures, but the low supervision mode caused the amount of rush purchasing for emergency supplies to continue to rise, resulting in a sharp increase in inventory shortages and leading to a lag effect.

Policy implementation restrained the rapid growth of the emergency supply rush rate in the short term and reduced inventory shortage to a certain extent. However, due to a lack of government supervision, the effect of prevention and control gradually declined or was even invalidated. In addition, the continuous deterioration of the epidemic situation led to a sharp rise in the expected inventory, eventually leading to a "rebound" in the inventory shortage. (a)

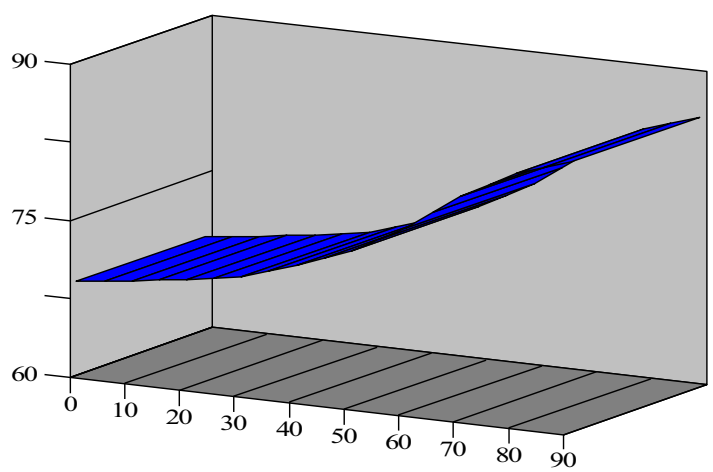

(c)

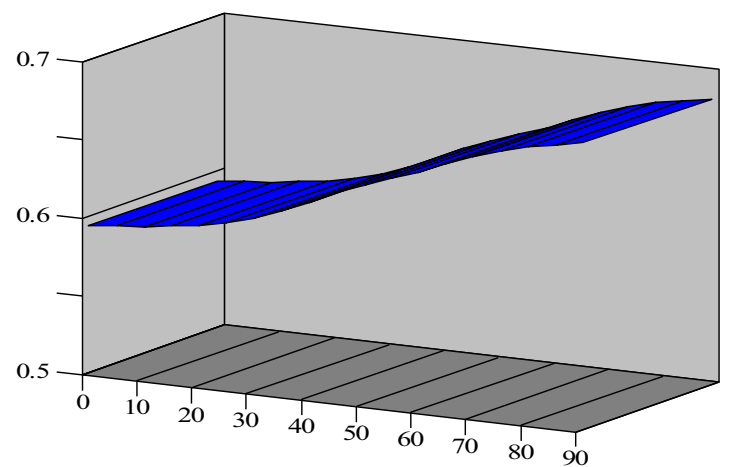

(b)

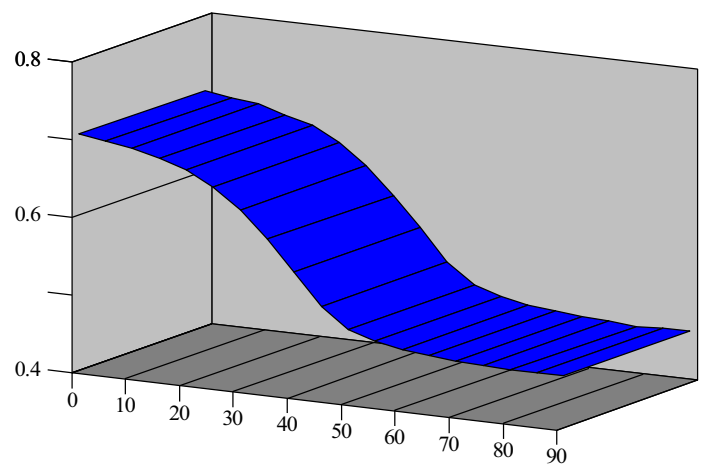

(d)

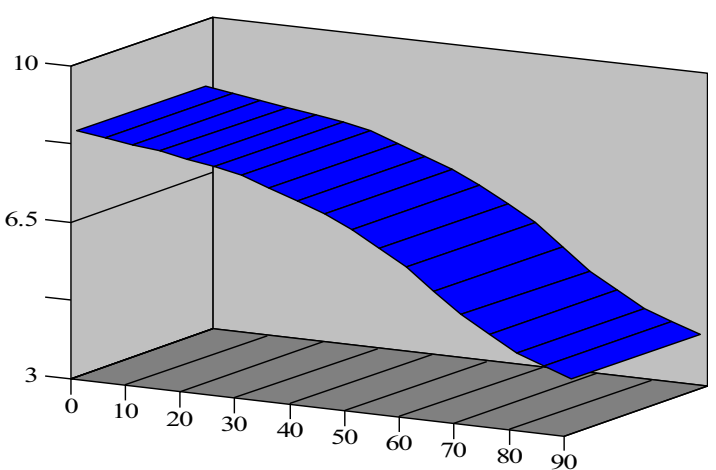

Fig. 5 Multiple performances of the strong supervision mode. a Government credibility; $\mathbf{b}$ rate of concealment and false declaration; $\mathbf{c}$ social benefit; $\mathbf{d}$ popularity of online public opinion 
(a)

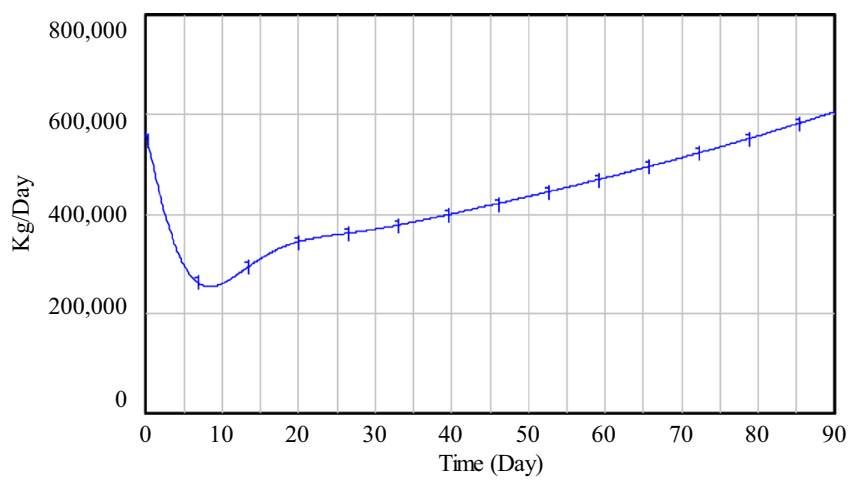

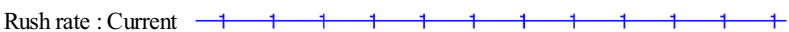

(c)

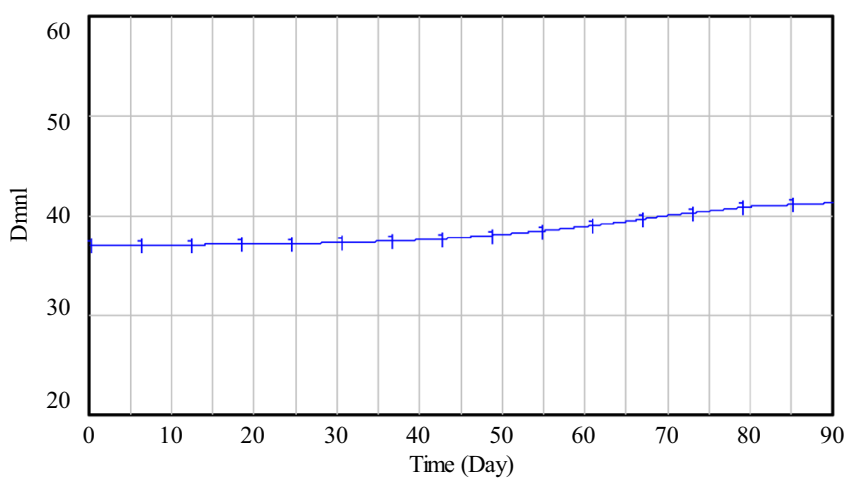

Public satisfaction : Current (b)

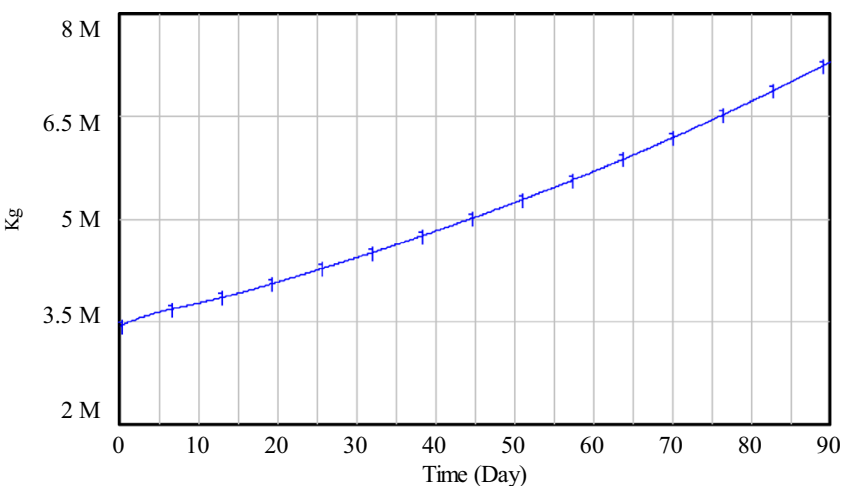

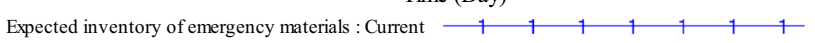

(d)

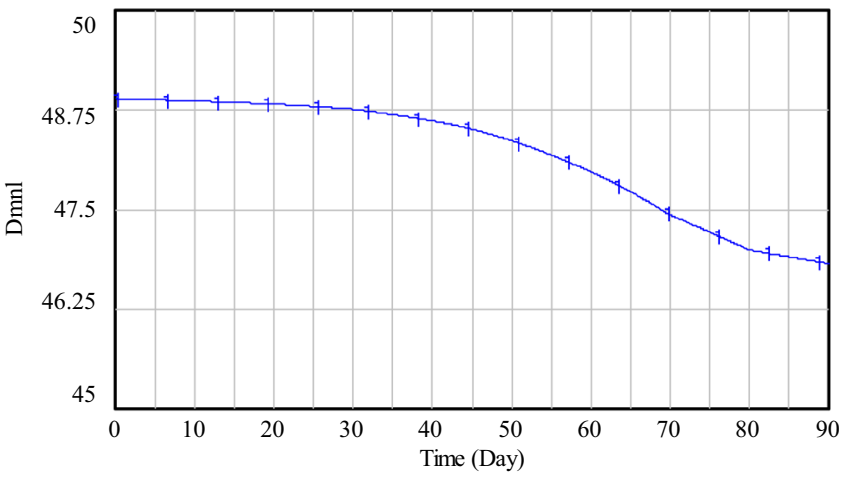

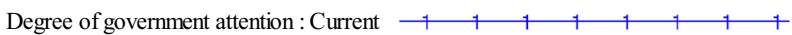

Fig. 6 Superposition effect under the low supervision mode. a Rush rate; $\mathbf{b}$ expected inventory of emergency materials; $\mathbf{c}$ public satisfaction; $\mathbf{d}$ degree of government attention

Similarly, Fig. $7 \mathrm{~b}$ and Table 4 show that the curve rises slowly (before the 30th day), only increasing by about $2.55 \%$, thus showing a lag phenomenon.

The above results show that the low supervision mode has lag effect (in the early stage) and a rebound effect (during the middle and late stages) on emergency material inventory balance. The effect of thrust efficiency on tackling key problems in science and technology is limited, showing an obvious lag.

(a)

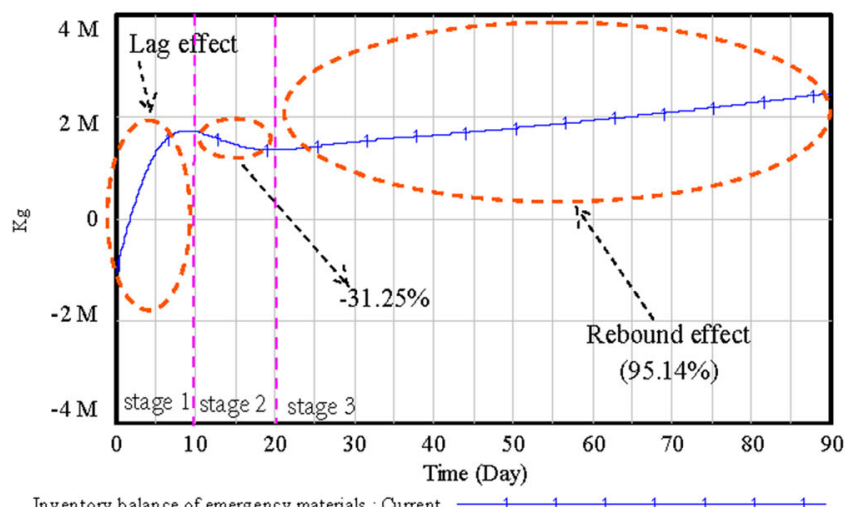

\section{Fading effect}

Although the strong supervision model has multiple performances (see Fig. 5 and Table 2), with the passage of time and the development of the epidemic, its effect will be gradually weakened or will even rebound.

Figure 8 and Table 5 (see Appendix) show that under the strong supervision mode, the degree of government data

(b)

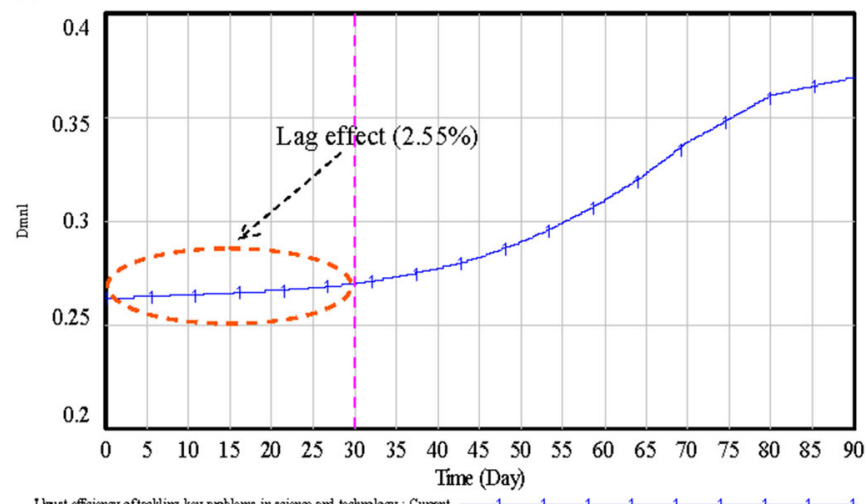

Fig. 7 Lag effect under the low supervision mode. a Inventory shortage of emergency materials; $\mathbf{b}$ thrust efficiency of tackling key problems in science and technology 
(a)

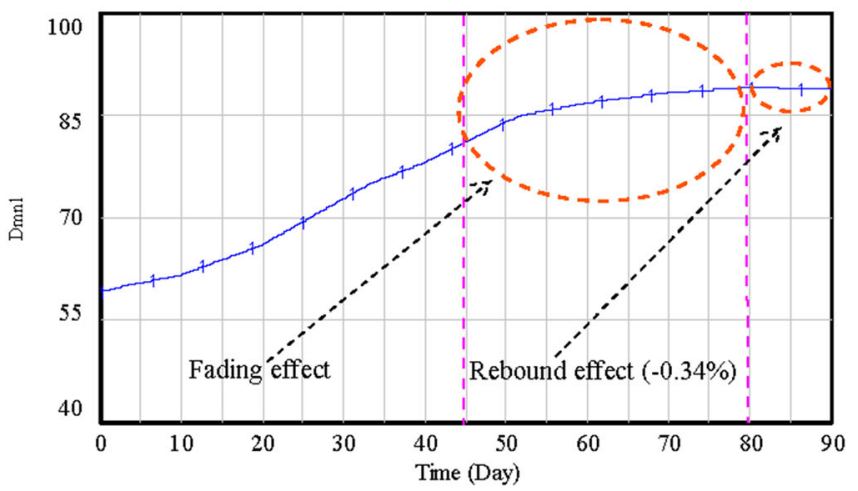

(b)

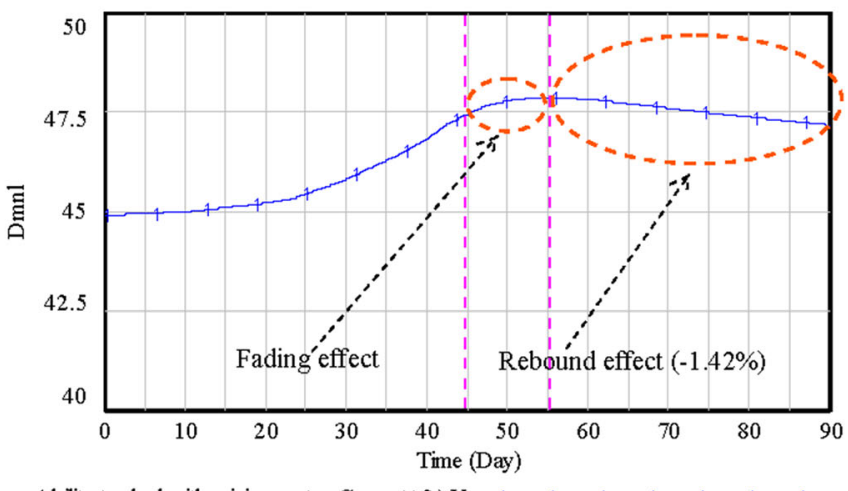

Degree of government data sharing: Current $+2 \Delta \mathrm{X}$

Ability to deal with crisis events : Current $+2 \Delta X$

Fig. 8 Fading effect under strong supervision mode. a Degree of government data sharing; $\mathbf{b}$ ability to deal with crisis events

sharing is greatly improved, reaching 88.70 at the end of the simulation, while the ability to deal with crisis events is at a medium level (44.91-47.16). The improvement in the degree of government data sharing is conducive to improving the thrust efficiency of tackling key problems in science and technology. Improving the ability to deal with crisis events and the thrust efficiency of tackling key problems in science and technology can promote social benefit.

The following results can also be obtained from Fig. 8 and Table 5: In Fig. 8a and Table 5, the growth rate of the curve decreases gradually (from the 45th day to the 80th day) from 3.85 to 0.43 , resulting in fading effect. After the 80th day, there are signs of rebound, but the effect is not significant $(-0.34 \%)$. In Fig. 8b, the curve rises slowly (between 45 and 55 days), and after the 55 th day, there is a rebound $(-1.42 \%)$.

\section{Conclusions}

In consideration of the harm of COVID-19 to human health and society, this study took the supply of agricultural products (e.g., vegetables) as an example and used causal feedback analysis to analyze the interactions between public opinion dissemination, material supply, staggered work shifts, public awareness, legal warning effect, and the subsystem of scientific and technological research and social benefit to establish a prevention and control model. The main conclusions are summarized below.

First, the public's cognitive beliefs, the ability to deal with crisis events, thrust efficiency in tackling key problems in science and technology, and the rate of concealment and false declaration are the main factors for improving social benefit.

Second, under the low supervision mode, the combined effects of rush rate, public satisfaction, degree of government attention, and other factors cause the expected inventory of emergency supplies continue to increase, resulting in a superposition effect. The low supervision mode has a lag effect on the inventory shortage of emergency materials and thrust efficiency for tackling key problems in science and technology. On the one hand, policy implementation needs a period of time to play a role, and the effect is not significant. On the other hand, with the development of the epidemic, the rush rate, degree of government attention, and public satisfaction continue to deteriorate, further aggravating the degree of public panic. In view of the superposition effect in the process of epidemic prevention and control, a combined strategy is suggested that includes administrative measures, economic measures, legal measures, and technical measures. A strict supervision mode should be adopted to curb the rapid rise in the rush rate and the inventory shortage of emergency materials, reduce the rate of concealment and false declaration, and further weaken the harm caused by the lag effect and superposition effect.

Finally, strong supervision measures can promote government credibility, inhibit online public opinion dissemination and the rate of concealment and false declaration, and improve social benefit. Although strong supervision measures have multiple performances, they will nevertheless see a fading effect in the long term. For the fading effect of the prevention and control strategy, timely adjustments should be made in terms of scope and strength to continuously improve and optimize the existing scenario. With regard to managing online public opinion dissemination, there is a need to strengthen publicity and guidance, enhance public awareness, and thereby reduce the rush buying of emergency materials. By relieving rush buying and improving science and technology's boosting efficiency, public satisfaction can be improved, participation by Internet users and media can be effectively guided, and online public opinion can be cooled.

There are still some limitations in this study. On the one hand, due to the setting of system boundary, some secondary factors are not written into the model. Through dynamic simulation, the medium- and long-term development trends of the main factors are discussed, but more refined data are not obtained. On the other hand, in view of the limited data, this article focuses on the analysis of the social benefit by the 
strong supervision mode. However, the environmental and economic benefits (Irfan et al. 2021c) of the model have not been further discussed, which are the areas that need to be improved in the future.

\section{Appendix}

Table 2 Influence of the strong supervision mode on different variables
Table 3 Influence of low supervision mode on main variables

\begin{tabular}{lllll}
\hline Time & $\begin{array}{l}\text { Government } \\
\text { credibility }\end{array}$ & $\begin{array}{l}\text { Rate of concealment and false } \\
\text { declaration }\end{array}$ & $\begin{array}{l}\text { Social } \\
\text { benefit }\end{array}$ & $\begin{array}{l}\text { Popularity of online public } \\
\text { opinion }\end{array}$ \\
\hline 1 & 69.06 & 0.7020 & 0.5942 & 8.4672 \\
5 & 69.30 & 0.6981 & 0.5955 & 8.4063 \\
10 & 69.62 & 0.6932 & 0.5972 & 8.3277 \\
15 & 69.96 & 0.6837 & 0.5996 & 8.2420 \\
20 & 70.32 & 0.6744 & 0.6020 & 8.1506 \\
25 & 70.34 & 0.6564 & 0.6056 & 8.0465 \\
30 & 71.18 & 0.6309 & 0.6101 & 7.9338 \\
35 & 72.03 & 0.5963 & 0.6173 & 7.7205 \\
40 & 72.90 & 0.5589 & 0.6248 & 7.5013 \\
45 & 73.86 & 0.5182 & 0.6331 & 7.2591 \\
50 & 74.88 & 0.4932 & 0.6398 & 7.0016 \\
55 & 76.28 & 0.4821 & 0.6462 & 6.6480 \\
60 & 77.68 & 0.4759 & 0.6520 & 6.2942 \\
65 & 79.50 & 0.4721 & 0.6591 & 5.8310 \\
70 & 81.36 & 0.4684 & 0.6663 & 5.3592 \\
75 & 82.74 & 0.4667 & 0.6716 & 5.0070 \\
80 & 84.13 & 0.4650 & 0.6769 & 4.6514 \\
85 & 84.99 & 0.4660 & 0.6799 & 4.4308 \\
90 & 85.85 & 0.4670 & 0.6829 & 4.2107 \\
\hline
\end{tabular}

\begin{tabular}{lllll}
\hline Time & $\begin{array}{l}\text { Rush rate }(\mathrm{kg} / \\
\text { day) }\end{array}$ & $\begin{array}{l}\text { Expected inventory of emergency } \\
\text { materials }(\mathrm{kg})\end{array}$ & $\begin{array}{l}\text { Public } \\
\text { satisfaction }\end{array}$ & $\begin{array}{l}\text { Degree of government } \\
\text { attention }\end{array}$ \\
\hline 1 & 495,618 & $3.48669 \mathrm{e}+006$ & 31.51 & 49.11 \\
5 & 271,773 & $3.64618 \mathrm{e}+006$ & 31.53 & 49.10 \\
10 & 243,935 & $3.76725 \mathrm{e}+006$ & 31.57 & 49.08 \\
15 & 320,579 & $3.90482 \mathrm{e}+006$ & 31.60 & 49.06 \\
20 & 354,610 & $4.07406 \mathrm{e}+006$ & 31.65 & 49.04 \\
25 & 357,908 & $4.25231 \mathrm{e}+006$ & 31.70 & 49.02 \\
30 & 366,274 & $4.43247 \mathrm{e}+006$ & 31.78 & 48.98 \\
35 & 383,158 & $4.61881 \mathrm{e}+006$ & 31.92 & 48.91 \\
40 & 401,025 & $4.81401 \mathrm{e}+006$ & 32.08 & 48.83 \\
45 & 417,780 & $5.01789 \mathrm{e}+006$ & 32.30 & 48.73 \\
50 & 434,890 & $5.23016 \mathrm{e}+006$ & 32.59 & 48.59 \\
55 & 453,079 & $5.45120 \mathrm{e}+006$ & 32.96 & 48.40 \\
60 & 472,175 & $5.68153 \mathrm{e}+006$ & 33.39 & 48.20 \\
65 & 492,008 & $5.92155 \mathrm{e}+006$ & 33.90 & 47.95 \\
70 & 512,602 & $6.17164 \mathrm{e}+006$ & 34.51 & 47.65 \\
75 & 534,127 & $6.43222 \mathrm{e}+006$ & 34.95 & 47.44 \\
80 & 556,529 & $6.70372 \mathrm{e}+006$ & 35.41 & 47.21 \\
85 & 579,985 & $6.98664 \mathrm{e}+006$ & 35.59 & 47.13 \\
90 & 604,396 & $7.22154 \mathrm{e}+006$ & 35.76 & 47.04 \\
\hline & & & &
\end{tabular}


Table 4 Influence of low supervision mode on inventory shortages of emergency materials and the thrust efficiency of tackling key problems in science and technology

\begin{tabular}{llllll}
\hline $\begin{array}{l}\text { Time } \\
\text { Inventory shortage of } \\
\text { emergency materials }(\mathrm{kg})\end{array}$ & $\begin{array}{l}\text { Thrust efficiency of tackling key } \\
\text { problems in science and technology }\end{array}$ & Time & $\begin{array}{l}\text { Inventory shortage of } \\
\text { emergency materials (kg) }\end{array}$ & $\begin{array}{l}\text { Thrust efficiency of tackling key } \\
\text { problems in science and technology }\end{array}$ \\
\hline 1 & $-4.46215 \mathrm{e}+005$ & 0.2627 & 50 & $1.76786 \mathrm{e}+006$ & 0.2896 \\
5 & $1.48942 \mathrm{e}+006$ & 0.2633 & 55 & $1.84259 \mathrm{e}+006$ & 0.2990 \\
10 & $1.83125 \mathrm{e}+006$ & 0.2641 & 60 & $1.91933 \mathrm{e}+006$ & 0.3097 \\
15 & $1.36018 \mathrm{e}+006$ & 0.2651 & 65 & $1.99964 \mathrm{e}+006$ & 0.3225 \\
20 & $1.25890 \mathrm{e}+006$ & 0.2661 & 70 & $2.08351 \mathrm{e}+006$ & 0.3378 \\
25 & $1.41025 \mathrm{e}+006$ & 0.2676 & 75 & $2.17091 \mathrm{e}+006$ & 0.3487 \\
30 & $1.52295 \mathrm{e}+006$ & 0.2694 & 80 & $2.26206 \mathrm{e}+006$ & 0.3603 \\
35 & $1.57361 \mathrm{e}+006$ & 0.2729 & 85 & $2.35722 \mathrm{e}+006$ & 0.3647 \\
40 & $1.62503 \mathrm{e}+006$ & 0.2769 & 90 & $2.45663 \mathrm{e}+006$ & 0.3689 \\
45 & $1.69351 \mathrm{e}+006$ & 0.2824 & --- & --- & -- \\
\hline
\end{tabular}

Table 5 Effect of strong supervision model on the degree of government data sharing and ability to deal with crisis events.

\begin{tabular}{lllll}
\hline Time & $\begin{array}{l}\text { Degree of government data } \\
\text { sharing }\end{array}$ & $\begin{array}{l}\text { Variation } \\
(\%)\end{array}$ & $\begin{array}{l}\text { Ability to deal with crisis } \\
\text { events }\end{array}$ & $\begin{array}{l}\text { Variation } \\
(\%)\end{array}$ \\
\hline 1 & 59.30 & -- & 44.91 & -- \\
5 & 60.38 & 1.82 & 44.94 & 0.07 \\
10 & 61.50 & 1.85 & 44.98 & 0.09 \\
15 & 63.75 & 3.66 & 45.09 & 0.24 \\
20 & 66.00 & 3.53 & 45.20 & 0.24 \\
25 & 69.38 & 5.12 & 45.43 & 0.51 \\
30 & 72.75 & 4.86 & 45.79 & 0.79 \\
35 & 75.75 & 4.12 & 46.27 & 1.05 \\
40 & 78.00 & 2.97 & 46.81 & 1.17 \\
45 & 81.00 & 3.85 & 47.28 & 1.00 \\
50 & 84.00 & 3.70 & 47.78 & 1.06 \\
55 & 85.63 & 1.94 & 47.84 & 0.13 \\
60 & 86.75 & 1.31 & 47.82 & -0.04 \\
65 & 87.50 & 0.86 & 47.70 & -0.25 \\
70 & 88.25 & 0.86 & 47.59 & -0.23 \\
75 & 88.63 & 0.43 & 47.48 & -0.23 \\
80 & 89.00 & 0.42 & 47.37 & -0.23 \\
85 & 88.85 & -0.17 & 47.27 & -0.21 \\
90 & 88.70 & -0.17 & 47.16 & -0.23 \\
\hline & & & &
\end{tabular}

Acknowledgements We are thankful to the anonymous reviewers. We thank LetPub (www.letpub.com) for its linguistic assistance during the preparation of this manuscript.

Author contribution Shuwei Jia contributed to data analysis and writing the manuscript; Yao Li and Tianhui Fang contributed to data analysis.

Funding This research was supported by the National Natural Science Foundation of China (grant no. 11901167), project funded by China Postdoctoral Science Foundation (grant no. 2021M690889), Social Science Planning Foundation of Henan Province (grant no.
2019BJJ038), Soft Science Key Research Project of Henan Province (grant no. 202400410051), Special Fund for Topnotch Talent at Henan Agricultural University (grant no. 30500646), and Soft Science Research Project of Zhengzhou (grant no. 2020RKXF0098).

Data availability Not applicable.

\section{Declarations}

Ethics approval and consent to participate This article does not involve the ethical problem. 
Consent for publication Not applicable.

Competing interests The authors declare no competing interests.

\section{References}

Abu-Rayash A, Dincer I (2020) Analysis of the electricity demand trends amidst the COVID-19 coronavirus pandemic. Energy Res Soc Sci 68:101682

Ahmad M, Akhtar N, Jabeen G, Irfan M, Anser MK, Wu H, Iş1k C (2021) Intention-based critical factors affecting willingness to adopt novel coronavirus prevention in Pakistan: implications for future pandemics. Int J Environ Res Public Health 18:6167

Buhat CAH, Torres MC, Olave YH, Gavina MKA, Felix EFO, Gamilla GB, Verano KVB, Babierra AL, Rabajante JF (2021) A mathematical model of COVID-19 transmission between frontliners and the general public. Netw Model Anal Health Inform Bioinform 10(1):17

Carmen RS, Reinhart M (2020) How can we prevent a COVID-19 food crisis? World Economic Forum May 2020. https://www.weforum. org/agenda/2020/05/preventing-a-covid-19-food-crisis/. Accessed 31 Mar 2021

Chakraborty I, Maity P (2020) COVID-19 outbreak: migration, effects on society, global environment and prevention. Sci Total Environ 728: 138882

Coccia M (2020a) An index to quantify environmental risk of exposure to future epidemics of the COVID-19 and similar viral agents: theory and practice. Environ Res 19:110155

Coccia M (2020b) How (un)sustainable environments are related to the diffusion of COVID-19: the relation between coronavirus disease 2019, air pollution, wind resource and energy. Sustainability 12 : 9709

Coccia M (2021a) Effects of the spread of COVID-19 on public health of polluted cities: results of the first wave for explaining the dejà vu in the second wave of COVID-19 pandemic and epidemics of future vital agents. Environ Sci Pollut Res 28:19147-19154

Coccia M (2021b) High health expenditures and low exposure of population to air pollution as critical factors that can reduce fatality rate in COVID-19 pandemic crisis: a global analysis. Environ Res 199: 11133

Coccia M (2021c) The impact of first and second wave of the COVID-19 pandemic in society: comparative analysis to support control measures to cope with negative effects of future infectious diseases. Environ Res 197:111099

Elavarasan RM, Shafiullah G, Raju K, Mudgal V, Arif MT, Jamal T, Subramanian S, Balaguru VS, Reddy KS, Subramaniam U (2020) COVID-19: impact analysis and recommendations for power sector operation. Appl Energy 279:115739

Elavarasan RM, Pugazhendhi R, Shafiullah GM, Irfan M, AnvariMoghaddam A (2021) A hover view over effectual approaches on pandemic management for sustainable cities - the endowment of prospective technologies with revitalization strategies. Sustain Cities Soc 68:102789

Hamed A, Sobhy A, Nassar H (2021) Accurate classification of COVID19 based on incomplete heterogeneous data using a KNN variant algorithm. Arab J Sci Eng. https://doi.org/10.1007/s13369-02005212-z

Hassen HB, Elaoud A, Salah NB, Masmoudi A (2021) A SIR-Poisson model for COVID-19: evolution and transmission inference in the Maghreb central regions. Arab J Sci Eng 46:93-102

Hepburn C, O'Callaghan B, Stern N, Stiglitz J, Zenghelis D (2020) Will COVID-19 fiscal recovery packages accelerate or retard progress on climate change? Oxf Rev Econ Polit 36:S359-S381
Hoang A, Nižetić S, Olcer AI, Ong H, Chen W, Chong C, Thomas S, Bandh SA, Nguyen X (2021) Impacts of COVID-19 pandemic on the global energy system and the shift progress to renewable energy: opportunities, challenges, and policy implications. Energy Policy 154:112322

Hoch T, Touzeau S, Viet AF, Ezanno P (2018) Between-group pathogen transmission: from processes to modeling. Ecol Model 383:138-149

$\mathrm{Hu}$ Z, Ge Q, Li S, Jin L, Xiong M (2020) Artificial intelligence forecasting of covid-19 in China. arXiv preprint arXiv:2002.07112. Accessed 31 Mar 2021

Iqbal W, Tang YM, Chau KY, Irfan M, Mohsin M (2021) Nexus between air pollution and NCOV-2019 in China: application of negative binomial regression analysis. Proc Saf Environ 150:557-565

Irfan M, Zhang Q, Sroufe R, Ferasso M (2020) The social dimensions of corporate sustainability: an integrative framework including COVID-19 insights. Sustainability 12:8747

Irfan M, Ikram M, Ahmad M, Wu H, Hao Y (2021a) Does temperature matter for COVID-19 transmissibility? Evidence across Pakistani provinces. Environ Sci Pollut Res. https://doi.org/10.1007/s11356021-14875-6

Irfan M, Akhtar N, Ahmad M, Shahzad F, Elavarasan RM, Wu H, Yang $\mathrm{C}$ (2021b) Assessing public willingness to wear face masks during the COVID-19 pandemic: fresh insights from the theory of planned behavior. Int J Environ Res Public Health 18:4577

Irfan M, Ahmad M, Fareed Z, Iqbal N, Sharif A, Wu H (2021c) On the indirect environmental outcomes of COVID-19: short-term revival with futuristic long-term implications. Int J Environ Health Res 2:111

Kuzemko C, Bradshaw M, Bridge G, Goldthau A, Jewell J, Overland I, Scholten D, de Graaf T, Westphal K (2020) COVID-19 and the politics of sustainable energy transitions. Energy Res Soc Sci 68: 101685

Li D (2020) Community prevention guidance for novel coronavirus pneumonia. Herald Med 39(3):315-318 (in Chinese)

Li J, Zhang W, Bai X, Li S, He K (2015) System-dynamics-based factor analysis for the speed of emergency materials transportation. Syst Eng-Theory Pract 35(3):661-670 (in Chinese)

Malki Z, Atlam ES, Ewis A, Dagnew G, Ghoneim O, Mohamed A, Abdel-Daim M, Gad I (2021) The COVID-19 pandemic: prediction study based on machine learning models. Environ Sci Pollut Res 28: 40496-40506. https://doi.org/10.1007/s11356-021-13824-7

Marbouh D, Abbasi T, Maasmi F, Omar I, Debe M, Salah K, Jayaraman R, Ellahham S (2020) Blockchain for COVID-19: review, opportunities and a trusted tracking system. Arab J Sci Eng 45:9895-9911

Mehrotra P, Malani P, Yadav P (2020) Personal protective equipment shortages during COVID-19 - supply chain-related causes and mitigation strategies. JAMA Health Forum 1(5):e200553

Pirouz B, Haghshenas SS, Haghshenas SS, Piro P (2020) Investigating a serious challenge in the sustainable development process: analysis of confirmed cases of COVID-19 (new type of coronavirus) through a binary classification using artificial intelligence and regression analysis. Sustainability 12(6):1-21

Rahimi NR, Fouladi-Fard R, Aali R, Shahryari A, Rezaali M, Ghafouri Y, Ghalhari MR, Asadi-Ghalhari M, Farzinnia B, Gea OC, Fiore M (2021) Bidirectional association between COVID-19 and the environment: a systematic review. Environ Res 194:110692

Razzaq A, Sharif A, Aziz N, Irfan M, Jermsittiparsert K (2020) Asymmetric link between environmental pollution and COVID-19 in the top ten affected states of US: a novel estimations from quantile-on-quantile approach. Environ Res 191:110189

Reyad O, Karar ME (2021) Secure CT-image encryption for COVID-19 infections using HBBS-based multiple key-streams. Arab J Sci Eng 46:3581-3593

Riou J, Althaus CL (2020) Pattern of early human-to-human transmission of Wuhan 2019 novel coronavirus (2019-nCoV), December 2019 to January 2020. Eurosurveillance 25(4):1-5 
Roosa K, Lee Y, Luo R, Kirpich A, Rothenberg R, Hyman JM, Yan P, Chowell G (2020) Real-time forecasts of the COVID-19 epidemic in China from February 5th to February 24th, 2020. Infect Dis Model 5:256-263

Wang H, Ghosh A, Ding J, Sarkar R, Gao J (2021) Heterogeneous interventions reduce the spread of COVID-19 in simulations on real mobility data. Sci Rep 11(1):7809

World Health Organization (2020) Coronavirus disease 2019 (COVID19) situation report, 72

Wright R (2020) The world's largest coronavirus lockdown is having a dramatic impact on pollution in India. CNN 1 April 2020. https:// edition.cnn.com/2020/03/31/asia/coronaviruslockdown-impactpollution-india-intl-hnk/index.html. Accessed 31 Mar 2021

Yu L, Li L, Wu J, Tang L (2015) Emergency policy exploration for network public opinion crisis in water pollution accident by hazardous chemicals leakage based on systematic dynamics. Syst EngTheory Pract 35(10):2687-2697 (in Chinese)
Zhao Y, Peng Y, Xiao L, Li L (2015) On opinion propagation mechanism of collective panic buying under emergences. Syst Eng-Theory Pract 35(3):616-622 (in Chinese)

Zhao S, Shen M, Musa SS, Guo Z, Ran J, Peng Z, Zhao Y, Chong MKC, He D, Wang MH (2021) Inferencing superspreading potential using zero-truncated negative binomial model: exemplification with COVID-19. BMC Med Res Methodol 21(1):30

Zhou P, Yang XL, Wang XG, Hu B, Zhang L, Zhang W, Si HR, Zhu Y, Li B, Huang CL, Chen HD, Chen J, Luo Y, Guo H, Jiang RD, Liu MQ, Chen Y, Shen XR, Wang X, Zheng XS, Zhao K, Chen QJ, Deng F, Liu LL, Yan B, Zhan FX, Wang YY, Xiao GF, Shi ZL (2020) A pneumonia outbreak associated with a new coronavirus of probable bat origin. Nature 579:270-273

Publisher's note Springer Nature remains neutral with regard to jurisdictional claims in published maps and institutional affiliations. 